\title{
Actinomycosis mimicing advanced cancer
}

\author{
Marek Kaszuba', Romana Tomaszewska², Kazimierz Pityński ${ }^{3}$, \\ Piotr Grzanka1 ${ }^{1}$, Stanisława Bazan-Socha ${ }^{1}$, Jacek Musiał ${ }^{1}$ \\ 1 Department Chair of Internal Medicine, Jagiellonian University School of Medicine, Kraków, Poland \\ 2 Department of Pathomorphology, Jagiellonian University School of Medicine, Kraków, Poland \\ 3 Department of Gynecology and Obstetrics, Jagiellonian University School of Medicine, Kraków, Poland
}

\section{KEY WORDS}

Actinomyces, actinomycosis, intrauterine device
Correspondence to: Marek Kaszuba, MD, II Katedra Chorób Wewnętrznych, Uniwersytet Jagielloński, Collegium Medicum, ul. Skawińska 8, 31 -066 Kraków, Poland, phone: + 48-12-430-51-23 fax: + 48-12-430-53-14, e-mail:markas@op.pl Received: April 24, 2008 Revision accepted: July 3, 2008 Conflict of interest: none declared. Pol Arch Med Wewn. 2008; 118 (10): 581-584

Translated by Iwona Rywczak, $\mathrm{MD}, \mathrm{PhD}$

Copyright by Medycyna Praktyczna, Kraków 2008

\begin{abstract}
Actinomycosis is a rare infectious inflammatory disease caused by the bacteria of the Actinomyces species. Infection occurs following damage to the skin or mucous membrane. This report presents a case of a 50-year-old female patient with subfebrile temperature, weight loss and pain, who used to have an intrauterine device. Masses suggestive of an advanced cancer were detected in her pelvis and abdominal cavity. A diagnosis of actinomycosis was made after histopathological examination of the tissue sample.
\end{abstract}

INTRODUCTION Actinomycosis is a rare chronic or subacute infectious disease resulting in suppurative and granulomatous inflammation. The disease is caused by anaerobic or facultatively anaerobic, acid-resistant Gram-positive bacteria of Actinomyces species. In the past classified as fungi, they derive their name from the shape of their colonies, whose branched filamentous forms resemble traveling rays. In healthy subjects, $A c-$ tinomyces form part of normal flora of the oral cavity or less commonly, a part of the gastrointestinal tract and the genital tract. Actinomyces are thus rated among opportunistic microorganisms. Infections are endogenous and occur more commonly in males (M:F=3:1), usually in subjects aged $20-50 .^{1}$ The bacteria enter the body through the damaged mucous membrane or the skin, most commonly during tooth extractions, abdominal surgery or when having an intrauterine device (IUD) inserted. ${ }^{2}$ In locations with favorable growth conditions (anaerobic environment), Actinomyces provoke development of abscesses, having a tendency to form fistulas; they spread contiguously. In humans, actinomycosis is most commonly caused by Actinomyces israeli, Actinomyces propionica and Actinomyces naeslundi, although at least 39 species of this bacterium have been described. ${ }^{3} \mathrm{~A}$ distinctive feature of this type of inflammation is the presence of "actinomycosis grains", sulfur colonies in the form of $0.1-5 \mathrm{~mm}$ grains in purulent contents secreted from the fistula. A microscopic test along with the presence of distinctive macroscopic features of purulent discharge leads to a diagnosis, which should be confirmed by microbiological evaluation. Actinomycosis treatment involves surgical drainage of abscesses and the prolonged use of penicillins administered in high doses. ${ }^{4,5}$

CASE REPORT A 50-year-old female patient was admitted to the Department of Allergy and Immunology Jagiellonian University School of Medicine to diagnose a cause of subfebrile temperature and left-sided subcostal pain of 1.5 years' duration. She also complained of hip joint, knee joint and spinal pains. Within 4 months preceding hospitalization she lost $4 \mathrm{~kg}$. She did not report any urination or defecation disorders. The patient's father died of stomach cancer at the age of 49 . At 24, the patient had her gallbladder removed due to cholelithiasis. Physical examination revealed a mass of indistinct borders and a diameter of $\sim 5-10 \mathrm{~cm}$ that was found in the left subcostal area. The location was slightly tender to palpation. Furthermore, on the skin of the left shank, a $\sim 3 \mathrm{~mm}$ wide single ecchymosis was noticed, and the limb skin demonstrated livedo reticularis. Small ecchymoses on the limbs and the face had been self-reported. They subsided spontaneously. Laboratory tests performed prior to hospitalization showed increased levels of inflammatory markers, including erythrocyte sedimentation 
FIGURE 1 Pelvic contrast-enhanced computed tomography. A strongly enhancing, heterogeneous, tumorous infiltration of approx. $4 \mathrm{~cm}$ in diameter (see arrow) in the anatomical location of the right ovary

FIGURE 2 Abdominal contrast-enhanced computed tomography. A $10 \times 4 \mathrm{~cm}$ heterogeneous, strongly contrast enhancing infiltration, stretching to about $10 \mathrm{~cm}$ (see arrow) in the abdominal wall, within the left subcostal area

FIGURE 3 Material obtained by fine-needle aspiration biopsy. Characteristic Actinomyces colonies visible in purulent exsudate (hematoxylin-eosin staining, magnified by $100 \times)$
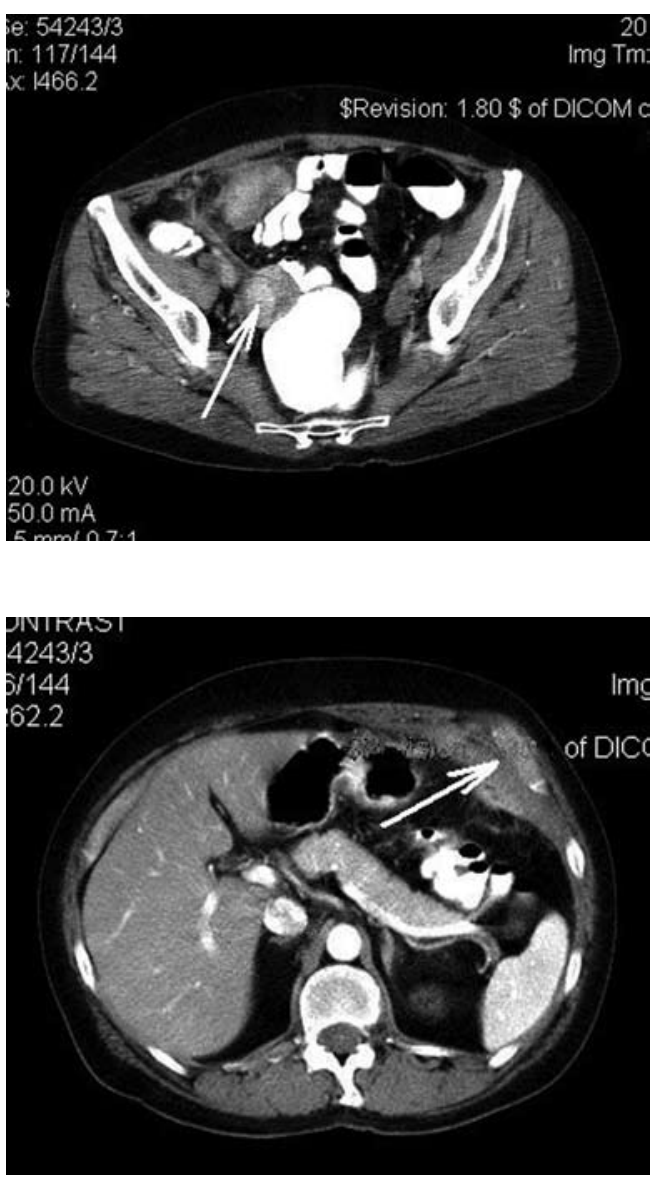

rate (ESR) $128 \mathrm{~mm} / \mathrm{h}, \mathrm{C}$-reactive protein (CRP) $23 \mathrm{mg} / \mathrm{l}$ (norm: <8 mg/l) and thrombocytosis 519,000/ $\mathrm{mm}^{3}$ (norm: $<440,000 / \mathrm{mm}^{3}$ ). Gastroscopy showed only hiatus hernia, and colonoscopy was normal.

During hospitalization, laboratory tests still demonstrated increased ESR and CRP levels and showed elevated levels of fibrinogen $-6.8 \mathrm{~g} / 1$ (norm: 1.8-3.5 g/l), alanine aminotransferase $72 \mathrm{U} / 1$ (norm: 14-36 U/l), aspartate aminotransferase - $92 \mathrm{U} / 1$ (norm: 14-36 U/1), $\gamma$-glutamyltranspeptidase - $54 \mathrm{U} / 1$ (norm: 12-43 U/1) and alkaline phosphatase - 140 U/1 (norm: 38-126 U/1) The X-rays of hip and knee joints did not reveal any abnormalities. The ultrasound examination of the abdomen and the pelvis demonstrated within the right ovary - a mass, about $4 \mathrm{~cm}$ in diameter, with about $6 \mathrm{~cm}$ long irregular hypoechoic

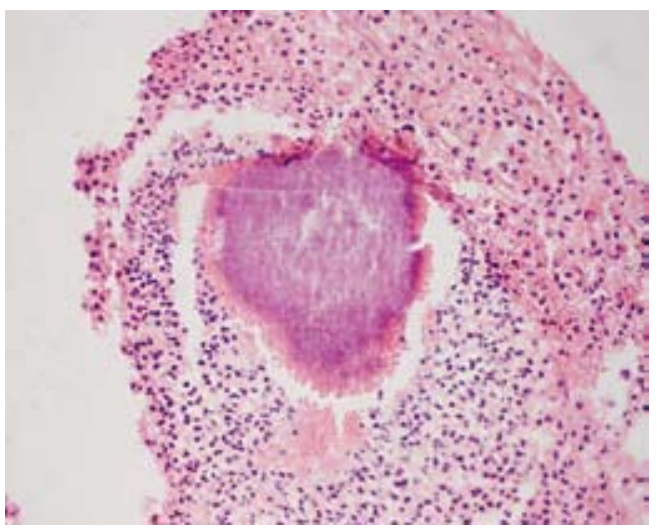

area getting wider towards the front and sides of the lesion. Contrast-enhanced computed tomography (CT) of the abdomen and the pelvis showed heterogeneous infiltration, $6 \mathrm{~cm}$ in $\mathrm{di}$ ameter in the anatomical location of the right ovary, intraperitoneally, with strong enhancement. Moreover, below this infiltrate, a small, belt-shaped fluid collection was observed (FIGURE 1), and in the abdominal wall, within the left subcostal area, the patient demonstrated a $10 \times 4 \mathrm{~cm}$ heterogeneous, strongly contrast enhancing infiltration (FIgUrE 2). The fine-needle aspiration biopsy of the abdominal wall lesion was performed. Cytology of the biopsy sample, performed in the Chair of Pathomorphology Jagiellonian University School of Medicine, showed pus with bacterial colonies typical of actinomycosis (FIGURE 3 ).

After initiating antibiotic therapy using amoxicillin-clavulanic acid, the patient was transferred to the department of gynecology. On surgery, a tumorous infiltration located in the abdominal wall in the right inguinal area and a similar infiltration in the bladder wall, which was connected with the right-sided inflammed, adnexa were removed. Moreover, the uterus with bilateral adnexa was resected. Palpation and inspection of the abdomen showed no other pathological lesions. The infiltration in the left-sided subcostal area, described earlier in the $\mathrm{CT}$ and ultrasound examination, subsided after antibiotic therapy and the pain disappeared.

Histological examination of the bladder tumor lesion showed the presence of a mixed-cell, reactive inflammatory infiltration was reported, whereas the material obtained from the right ovary and adnexa showed scattered unspecific infiltrations with granulation centers of an "around a foreign body" type were found. Within the fallopian tubes, purulent exsudates were observed (FIgURE 4). The described histopathological lesions may correspond to the picture of lesions found in actinomycosis.

DISCUSSION Depending on the lesion location, several forms of actinomycosis, i.e., cervicofacial, thoracic, abdominal and pelvic, can be distinguished. ${ }^{1}$ The patient demonstrated a rare, mixed abdominopelvic form. Available data points out the association between use of IUD and occurrence of pelvic actinomycosis. ${ }^{2,6,7}$ This is based on two observations. First, the common presence of Actinomyces in cervical smears obtained from users of IUD as compared to those who do not use IUD. ${ }^{7,8}$ Second, the invasive pelvic actinomycosis occurs nearly exclusively in women using IUD. ${ }^{8,9}$ The patient presented here reported a history of several years' use of IUD. It is highly probable that infection was transmitted through the genital tract. It seems that the original lesion was a tumorous infiltration of the right ovary mimicing the cancer, whereas infiltrations of the abdominal wall and the bladder could have been secondary. A few years earlier the patient had not undergone 
FIGURE 4 Surgical specimen - purulent contents in the fallopian tube (see asterisk); large, chronic, partly purulent, inflammatory infiltrations with numerous macrophages found in the wall of the fallopian tube and in the adjacent segment of the ovary (see arrows) (hematoxylin-eosin stain, magnified $200 \times$ )

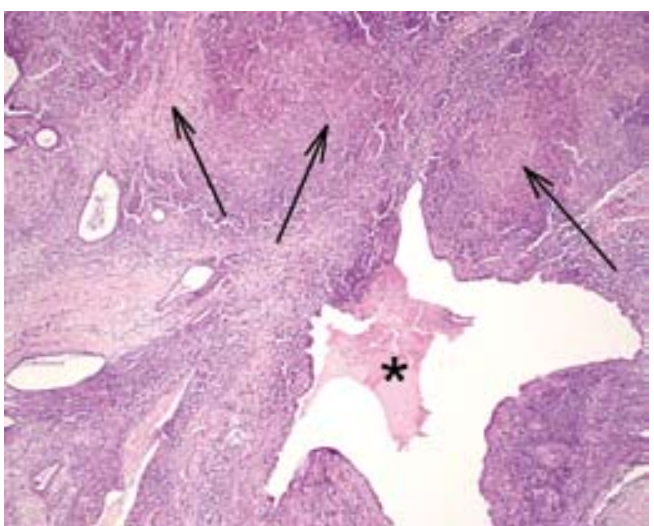

12 Wagenlehner FM, Mohren B, Naber KG, et al. Abdominal actinomycosis. Clin Microbiol Infect. 2003; 9: 881-885.

13 Weese WC, Smith IM. A study of 57 cases of actinomycosis over a 36-year period. A diagnostic "failure" with good prognosis after treatment. Arch Intern Med. 1975; 135: 1562-1568. any surgery within the abdominal cavity and abdominal actinomycosis is most commonly associated with surgical procedures.

In order to prevent invasive actinomycosis, users of IUDs, in whom Actinomyces were detected in the cervical smear, should be suggested to remove the intrauterine device, and those, who plan to insert an IUD, should be firmly advised against it. Examination of the cervical canal contents for the presence of Actinomyces in those patients could undoubtedly reduce the incidence of the invasive form of pelvic actinomycosis.

Actinomycotic lesions, with the concomitantly affected pelvis and abdominal cavity have rarely been described. Such manifestations are most commonly encountered in case of cancer located originally in the ovary. ${ }^{4}$ The described case indicates that in differential diagnosis of such lesions, except for cancer, an infection, like actinomycosis, should also be considered. ${ }^{10-12}$ In the latter case, even with highly advanced local lesions, prognosis is quite good on condition of an accurate diagnosis and the implementation of appropriate therapy. $4,5,13$

\section{REFERENCES}

1 Schaal KP, Lee HJ. Actinomycete infections in humans - a review. Gene 1992; 115: 201-211.

2 Arend SM, Oosterhof $\mathrm{H}$, van Dissel JT. Actinomyces and the intrauterine device. Arch Intern Med. 1998; 158: 1270.

3 Clarridge JE, Zhang 0 . Genotypic diversity of clinical Actinomyces species: phenotype, source, and disease correlation among genospecies. J Clin Microbiol. 2002; 40: 3442-3448.

4 Hamid D, Baldauf $\mathrm{JJ}$, Cuenin C, et al. Treatment strategy for pelvic actinomycosis: case report and review of the literature. Eur J Obstet Gyneco Reprod Biol. 2000; 89: 197-200.

5 Smith AJ, Hall V, Thakker B, et al. Antimicrobial susceptibility testing of Actinomyces species with 12 antimicrobial agents. J Antimicrob Chemother. 2005; 56: 407-409.

6 Soria-Aledo V, Flores-Pastor B, Carrasco-Prats M, et al. Abdominopelvic actinomycosis: a serious complication in intrauterine device users. Acta Obstet Gynecol Scand. 2004; 83: 863-865.

7 Valicenti JF, Pappas AA, Graber CD, et al. Detection and prevalence of IUD-associated Actinomyces colonization and related morbidity: a prospective study of 69,925 cervical smears. JAMA. 1982; 247 : 1149-1152.

8 Evans DTP. Actinomyces israelii in the female genital tract: a review. Genitourin Med. 1993; 69: 54-59.

9 Fiorino AS. Intrauterine contraceptive device-associated actinomycotic abscess and Actinomyces detection on cervical smear. Obstet Gynecol. 1996; 87: 142-149.

10 Belmont MJ, Behar PM, Wax MK. Atypical presentations of actinomycosis. Head Neck. 1999; 21: 264-268.

11 Cintron JR, Del Pino A, Duarte B, et al. Abdominal actinomycosis. Dis Colon Rectum. 1996; 39: 105-108. 